Article

\title{
Association between Genetic Variants in DNA Double-Strand Break Repair Pathways and Risk of Radiation Therapy-Induced Pneumonitis and Esophagitis in Non-Small Cell Lung Cancer
}

\author{
Lina Zhao ${ }^{1,2}$, Xia Pu ${ }^{1}$, Yuanqing Ye ${ }^{1}$, Charles $\mathrm{Lu}^{3}$, Joe Y. Chang ${ }^{4}$ and Xifeng $\mathrm{Wu}^{1, *}$ \\ 1 Department of Epidemiology, The University of Texas MD Anderson Cancer Center, 1515 Holcombe Blvd, \\ Houston, TX 77030, USA; zhaolinazln@outlook.com (L.Z.); ipuxia@gmail.com (X.P.); \\ yqye@mdanderson.org (Y.Y.) \\ 2 Department of Radiation Oncology, Xijing Hospital, Fourth Military Medical University, Xi'an 710032, China \\ 3 Department of Thoracic/Head and Neck Medical Oncology, The University of Texas MD Anderson Cancer \\ Center, 1515 Holcombe Blvd, Houston, TX 77030, USA; jychang@mdanderson.org \\ 4 Departement of Radiation Oncology, The University of Texas MD Anderson Cancer Center, 1515 Holcombe \\ Blvd, Houston, TX 77030, USA; clu@mdanderson.org \\ * Correspondence: xwu@mdanderson.org; Tel.: +1-713-745-2485; Fax: +1-713-792-4657
}

Academic Editor: Bingliang Fang

Received: 2 September 2015; Accepted: 14 February 2016; Published: 18 February 2016

\begin{abstract}
Radiation therapy (RT)-induced pneumonitis and esophagitis are commonly developed side effects in non-small cell lung cancer (NSCLC) patients treated with definitive RT. Identifying patients who are at increased risk for these toxicities would help to maximize treatment efficacy while minimizing toxicities. Here, we systematically investigated single nucleotide polymorphisms (SNPs) within double-strand break (DSB) repair pathway as potential predictive markers for radiation-induced esophagitis and pneumonitis. We genotyped 440 SNPs from 45 genes in DSB repair pathways in 250 stage I-III NSCLC patients who received definitive radiation or chemoradiation therapy, followed by internal validation in 170 additional patients. We found that 11 SNPs for esophagitis and $8 \mathrm{SNPs}$ for pneumonitis showed consistent effects between discovery and validation populations (same direction of OR and reached significance in meta-analysis). Among them, rs7165790 in the BLM gene was significantly associated with decreased risk of esophagitis in both discovery $(\mathrm{OR}=0.59,95 \% \mathrm{CI}: 0.37-0.97, p=0.037)$ and validation subgroups $(\mathrm{OR}=0.45,95 \%$ CI: $0.22-0.94, p=0.032$ ). A strong cumulative effect was observed for the top SNPs, and gene-based tests revealed 12 genes significantly associated with esophagitis or pneumonitis. Our results support the notion that genetic variations within DSB repair pathway could influence the risk of developing toxicities following definitive RT in NSCLC.
\end{abstract}

Keywords: NSCLC; radiation pneumonitis and esophagitis; DNA double-stranded break repair pathway; single nucleotide polymorphism

\section{Introduction}

Radiation therapy (RT) is the primary care for locally advanced non-small cell lung cancer (NSCLC). However, while resulting in tumor shrinkage, RT also leads to damage of surrounding normal tissues and caused normal tissue toxicities [1]. Commonly occurred RT-induced toxicities have limited the planed dose and therefore compromised the efficiency of local and/or regional control and negatively influence patients' prognosis. Accurate prediction before treatment will therefore enable 
personalized dosimetric design, and maximize treatment effect while minimizing potential toxicities. Currently, the risk of RT-induced toxicities were assessed based on clinical-based factors, including physical characteristics of the radiation beam; treatment dose, fractionation and time; volume and type of normal tissue receiving radiation; radiosensitizer usage; and comorbidities [2]. However, large variation exists in patients with similar clinical parameters. It suggests a potential role of host genetic factors in determining an individual's response to RT and therefore susceptibility of developing RT-induced toxicities [3].

Generally, DNA double-strand breaks (DSBs) are the major genotoxic lesions induced by ionization radiation. There are two distinct and complementary pathways for DSB repair, namely, homologous recombination (HR) and non-homologous end joining (NHEJ). DSBs repairing play a key role in maintaining genomic stability and integrity after RT [4]. It has been reported that deficiencies in DSB repair genes were associated with high incidence of chromosome aberrations and increased tumor radiation sensitivity [5-8]. Therefore, it is reasonable to presume that variants in DSB repair pathway genes could modify the radiosensitivity as well as clinical outcomes after RT.

Several studies have reported the association between SNPs in several DSB repair pathway genes and RT-induced esophagitis and pneumonitis, such as BRCA1 [9], ATM [10,11], P53 [10], RAD51 [4] and LIG4 [12]. However, these studies mainly used single gene-based approach without validation of their findings. We have previously used pathway-based approaches to identify genetic variations in inflammation pathway genes as predictors of radiation-induced toxicities in NSCLC patients [13], which provided more coverage compared to single-gene-based approaches. In this study, to the best of our knowledge, we, for the first time, utilized a pathway-based approach to investigate genetic variations within DSB pathway genes in a relatively large, well-characterized population and analyzed their role in developing esophagitis or pneumonitis following definitive RT with a validation step. Our goal is to identify potential DSB-related biomarkers which will be used to facilitate personalized dosage design.

\section{Materials and Methods}

\subsection{Study Population and Data Collection}

Study patients were newly diagnosed and histologically confirmed stage I-III NSCLC patients recruited between September 1995 and February 2008. All these patients had received chemoradiation therapy or definitive thoracic radiation at The University of Texas MD Anderson Cancer Center. Tumor staging was defined based on the 6th edition of American Joint Committee on Cancer (AJCC) staging. A structured questionnaire was used to collect epidemiological data during an in-person interview conducted by a well-trained staff interviewer. Clinical as well as follow-up information was abstracted from medical records. Pretreatment performance status was defined based on the Eastern Cooperative Oncology Group scale. Definitions of radiation-induced pneumonitis and esophagitis have been previously reported [13]. In brief, symptomatic pneumonitis was defined as clinical presentation of patients with respiratory complaints during and after radiation treatment, including dyspnea and chest pain in the setting of absence of evidence for infection. Similarly, for esophagitis, symptomatic complaints related to swallowing including dysphagia, odynophagia or chest discomfort at baseline during and after radiation treatment were included in the definition. Severity of esophagitis or pneumonitis was scored by the clinical physicians according to the National Cancer Institute Common Terminology Criteria for Adverse Events (version 3.0) guidelines [14]. For pneumonitis and esophagitis, toxicity was scored as grade 1 (asymptomatic: radiographic or endoscopic findings only), grade 2 (moderate symptoms: altered breathing or dietary habits requiring medical intervention), grade 3 (severe symptoms: oxygen indicated; unable to aliment orally), grade 4 (life-threatening: ventilator support indicated), or grade 5 (death). Final determination of radiation toxicities was determined by the considerations of patient clinical findings made by the treating radiation oncologist. Consistent with prior studies $[10,13,15,16]$, occurrence of grade $\geqslant 2$ toxicities was considered as an event in this 
study since grade 1 pneumonitis or esophagitis is clinically asymptomatic and does not require medical intervention. A blood sample was drawn from each participant for subsequent analysis. All patients signed an informed consent form, and the study was approved by the Institutional Review Board of MD Anderson.

\subsection{SNP Selection and Genotyping}

SNPs were genotyped using a custom Illumina iSelect Infinium II genotyping platform (Illumina, San Diego, CA) containing 9645 SNPs from 998 genes. The details for the chip design, including SNP and gene selection methods, have been described previously [17]. Briefly, tagging SNPs for each gene were selected from within a 10-kb flanking region using CEU data from the HapMap Project [18], based on the NCBI B36 assembly and dbSNP b126 by using the Tagger Pairwise method $\left(\mathrm{r}^{2}>0.8\right.$ and minor allele frequency $(\mathrm{MAF}) \geqslant 0.05)$ as reported previously [19]. SNPs located in the coding (synonymous and non-synonymous SNPs), in regulatory regions (promoter, $3^{\prime}$ or $5^{\prime}$-untranslated regions (UTRs)) or at splicing sites were also selected, and a SNP is also included if it has previously been reported as a potentially functional SNP with an MAF greater than $1 \%$ in the Caucasian population.

A total of 440 SNPs in 45 candidate genes in DNA DSB repair pathway were included in this panel (Supplementary Table S1). Genomic DNA was extracted from peripheral blood lymphocytes using the QIAamp DNA extraction kit (Qiagen, Valencia, CA, USA). Genotyping was performed according to the standard Infinium II assay protocol, and any DNA samples or SNPs with a call rate (percentage of data available for all SNPs or samples) $<95 \%$ were excluded from further analysis. For the validation phase, the genotyping was performed using HumanHap300k and 370k BeadChip (Illumina, San Diego, CA, USA). Quality control rules were similar to those used in the discovery phase-only SNPs and samples with a genotyping or sample call rate $>95 \%$ were included in the analysis.

\subsection{Statistical Analysis}

A Chi-square test and a Student's t-test were used to assess the distribution of covariates between patients with or without an event. Multivariate logistic regression was used to estimate the main effect of single SNP on risk of developing toxicities adjusted for age, sex, pack year, clinical stage, performance status, chemoradiotherapy, radiation treatment type, forced expiratory volume in the first second (FEV1), carbon monoxide diffusing capacity (DLCO) percentage, planning tumor volume (PTV), mean dose (mean esophagus dose for esophagitis and mean lung dose for pneumonitis). For each SNP dominant, recessive and additive models were analyzed, and only the best-fitting model were reported. In order to expand the coverage of the validation panel, we also included proxy SNPs that are in high linkage disequilibrium (LD > 80\%) with the original genotyped SNP from the discovery phase and analyzed in the validation population. The proxy SNPs were identified using SNAP [20] based on LD information calculated using phased genotype data from the International HapMap Project and the 1000 Genomes Project.

If the proxy SNPs showed a similar effect to the original SNP in the discovery phase, meta-analysis was performed to summarize the effects from discovery and validation populations. Heterogeneity was estimated using $\chi^{2}$-based Q-statistics. A fixed effect model was used when heterogeneity was absent ( $p$ for heterogeneity $<$ P-het $>>0.05$ ). An unfavorable genotype (UFG) was defined as the allele associated with an increased risk of developing toxicities. A joint analysis all UFGs for each patient and risk of esophagitis or pneumonitis was conducted with subjects stratified by level of risk in tertiles. All statistical analyses were two-sided. The analysis described above was performed using STATA software (version 10, STATA Corp, College Station, TX, USA).

HaploReg [21] was used for functional annotations of candidate SNPs. PolyPhen-2 [22], SNPeffect [23], SIFT [24] and SNPs3D [25] were used to predict the function of missense variant on protein function. VEGAS was used to perform gene-based tests, which produces a gene-based test statistic based on a simulation to calculate an empirical gene-based $p$-value [26]. 


\section{Results}

\subsection{Characteristics of Patients}

A total of 420 (250 in discovery, 170 in validation) Stage I-III NSCLC patients were included in this analysis. Table 1 summarizes the baseline clinical characteristics of patients in the discovery and validation phases, respectively. No statistically significant difference was observed between patients in the discovery and validation phases in terms of age, gender, smoking pack year, performance status, pulmonary function, PTV volume, mean esophagus dose or proportion of radiation-induced esophagitis. Patients in the validation phase had slightly lower mean lung dose (16 vs. 18 Gy), were less likely to receive concurrent chemoradiation therapy ( $35 \%$ vs. $74 \%$ ), more patients treated by IMRT, and less treated by 3D-CRT technique (41\% vs. 23\%) compared to the discovery phase.

Table 1. Patient characteristics.

\begin{tabular}{|c|c|c|}
\hline Variable & Discovery Phase, $n$ (\%) & Validation Phase, $n(\%)$ \\
\hline Age, mean (SD) & $62.9(10.1)$ & $63.9(9.9)$ \\
\hline Pack year, mean (SD) & $52.2(28.5)$ & $52.6(28.5)$ \\
\hline DLCO percentage, mean (SD) & $66.6(20.8)$ & $65.9(19.8)$ \\
\hline FEV1 percentage, mean (SD) & $71.5(18.1)$ & $66.7(21.1)$ \\
\hline PTV volume $\left(\mathrm{cm}^{3}\right)$, mean (SD) & $729.9(491.4)$ & $655.5(384.8)$ \\
\hline Mean esophagus dose, mean (SD) & $29.8(13.1)$ & $27.5(10.8)$ \\
\hline Mean lung dose, mean (SD) & $18.0(8.3)$ & $16.0(5.6)$ \\
\hline Median total dose (range) & $63(34.8-126)$ & $60(10.9-83.8)$ \\
\hline \multicolumn{3}{|l|}{ Sex } \\
\hline Male & $129(52)$ & $95(56)$ \\
\hline Female & $121(48)$ & $75(44)$ \\
\hline \multicolumn{3}{|l|}{ Clinical stage } \\
\hline I & $43(17)$ & $2(1)$ \\
\hline II & $40(16)$ & $9(5)$ \\
\hline IIIA & $92(37)$ & $113(66)$ \\
\hline IIIB & $75(30)$ & $46(27)$ \\
\hline \multicolumn{3}{|l|}{ Histology } \\
\hline Adenocarcinoma & $90(36)$ & $68(40)$ \\
\hline Large cell carcinoma & $13(5.2)$ & $8(4.7)$ \\
\hline Squamous cell carcinoma & $84(33.6)$ & $63(37)$ \\
\hline Other & $63(25.2)$ & $31(18.2)$ \\
\hline \multicolumn{3}{|l|}{ Performance status } \\
\hline 0 & $72(29)$ & $41(24)$ \\
\hline 1 & $117(47)$ & $73(43)$ \\
\hline $2-4$ & $23(9)$ & $22(13)$ \\
\hline \multicolumn{3}{|l|}{ Treatment modality } \\
\hline Radiation & $65(26)$ & $110(65)$ \\
\hline Concurrent chemoradiation & $185(74)$ & $60(35)$ \\
\hline Platinum-based only & 77 (41.6) & $21(35)$ \\
\hline Platinum plus taxane & $108(58.4)$ & $39(65)$ \\
\hline \multicolumn{3}{|l|}{ Radiation Type } \\
\hline $2 \mathrm{D}$ & $74(30)$ & $51(30)$ \\
\hline $3 \mathrm{D}$ & $105(42)$ & $40(24)$ \\
\hline IMRT & $58(23)$ & $69(41)$ \\
\hline Proton & $13(5)$ & $10(6)$ \\
\hline \multicolumn{3}{|l|}{ Esophagitis } \\
\hline No & $106(43)$ & $104(62)$ \\
\hline Yes & $143(57)$ & $65(38)$ \\
\hline \multicolumn{3}{|l|}{ Pneumonitis } \\
\hline No & $147(63)$ & $91(61)$ \\
\hline Yes & $87(37)$ & $58(39)$ \\
\hline Total & 250 & 170 \\
\hline
\end{tabular}

FEV1: forced expiratory volume in the first second; DLCO: carbon monoxide diffusing capacity; NOS: not otherwise specified; PTV: planning tumor volume; IMRT: intensity modulated radiotherapy, Numbers may not add to total due to missing clinical information. 


\subsection{Association between Individual SNPs and Esophagitis Risk}

A total of 440 SNPs were included in the discovery phase. Fifty SNPs in 20 genes were significantly associated with esophagitis ( $p$ value $<0.05$, Supplementary Table S2). Among them, genotyping data was available for 30 SNPs (15 original and 15 proxy SNPs (Supplementary Table S3). Among them, 11 SNPs showed the same trend of effects between discovery and validation populations and reached statistical significance in the combined meta-analysis (Table 2). Some of the SNPs profiled in the discovery were not found in the GWAS panel during validation; hence, proxy SNPs were selected and analyzed. Rs7165790 and its proxy SNP rs7175811 are intronic SNPs in BLM and showed consistent effect and significant association in the above two populations. The two SNPs were associated with a significantly decreased risk of esophagitis under the additive model (discovery: OR $=0.59,95 \%$ CI: $0.37-0.97, p=0.037$; validation: $\mathrm{OR}=0.45,95 \% \mathrm{CI}: 0.22-0.94, p=0.032$, respectively). Meta-analysis of the association of rs7165790 and rs7175811 with radiation esophagitis under the fixed effects model showed a $p$ value of 0.003 (OR $=0.54,95 \% \mathrm{CI}: 0.36-0.82, p$ for heterogeneity $=0.462)$.

\subsection{Association between Individual SNPs and Pneumonitis Risk}

31 SNPs in 17 genes were found to be associated with pneumonitis (Supplementary Table S4). Among the 31 SNPs, genotyping data was available for 23 SNPs (7 original SNPs and 16 proxy) in the validation phase (Supplementary Table S5). SNPs $\left(\mathrm{r}^{2}>0.8\right)$ were genotyped by GWAS. In total, 8 SNPs showed the same trend effect between the discovery and validation populations, and all of them reached significance by joint meta-analysis (Table 3).

\subsection{Cumulative Effects for Esophagitis or Pneumonitis Risk}

To analyze the cumulative effect of identified SNPs on radiation toxicities, we performed UFG analysis on both outcomes using the discovery population (Table 4). SNPs showing consistent effects between discovery and validation populations and reaching statistical significance in the meta-analysis were included in the UFG analysis. Significant dose-respond effects were identified for both esophagitis and pneumonitis risks as the number of unfavorable genotypes increased ( $p$ trend for the individual UFG was $2.59 \times 10^{-7}$ and $6.34 \times 10^{-8}$ respectively). The risk of developing esophagitis for patients carrying 6 to 7 unfavorable genotypes was increased 3.63-fold compared to those less than 6 risk genotypes $(p=0.003)$. The risk was dramatically increased 113.12-fold when 8 to 10 unfavorable genotypes were applied compared to patients with 0 to 5 UFGs $\left(p=5.46 \times 10^{-6}\right)$. The increased risk of developing pneumonitis for patients carrying 3 to 5 unfavorable genotypes was 8.65-fold higher compared to patients with 0 to 2 UFGs $\left(p=2 \times 10^{-4}\right)$. The risk was dramatically increased 73-fold when $6-8$ unfavorable genotypes were applied $\left(6.70 \times 10^{-6}\right)$. 
Table 2. Selected SNPs associated with radiation esophagitis.

\begin{tabular}{|c|c|c|c|c|c|c|c|c|c|c|}
\hline \multirow{2}{*}{ SNP } & \multirow{2}{*}{ Gene } & \multirow{2}{*}{ Allele } & \multirow{2}{*}{ Model } & \multicolumn{2}{|c|}{ Discovery } & \multicolumn{2}{|c|}{ Validation } & \multicolumn{3}{|c|}{ Meta } \\
\hline & & & & $\mathrm{OR}^{\#}(95 \% \mathrm{CI})$ & $p$ Value & $\mathrm{OR}^{\#}(95 \% \mathrm{CI})$ & $p$ value & OR $(95 \%$ CI $)$ & $p$ Value & P-het \\
\hline rs7165790 \& & BLM & $A>G$ & add & $0.59(0.37-0.97)$ & 0.037 & $0.45(0.22-0.94)$ & 0.032 & $0.54(0.36-0.82)$ & 0.003 & 0.462 \\
\hline rs8176257^ & BRCA1 & $\mathrm{C}>\mathrm{A}$ & rec & $5.42(1.47-20.03)$ & 0.011 & $3.18(0.75-13.49)$ & 0.116 & $4.27(1.62-11.24)$ & 0.003 & 0.592 \\
\hline rs2270132^ & BLM & $A>C$ & dom & $2.59(1.27-5.26)$ & 0.009 & $1.75(0.65-4.74)$ & 0.268 & $2.27(1.27-4.04)$ & 0.005 & 0.533 \\
\hline rs12516* & BRCA1 & $\mathrm{G}>\mathrm{A}$ & rec & $3.89(1.12-13.54)$ & 0.032 & $3.31(0.79-13.79)$ & 0.100 & $3.63(1.42-9.28)$ & 0.007 & 0.866 \\
\hline rs1799966 ^ & BRCA1 & $A>G$ & rec & $3.89(1.12-13.54)$ & 0.032 & 3.31 (0.79-13.79) & 0.100 & $3.63(1.42-9.28)$ & 0.007 & 0.866 \\
\hline rs4873772 * & PRKDC & $G>A$ & rec & $7.17(1.77-29.05)$ & 0.006 & $1.28(0.30-5.46)$ & 0.743 & $3.06(0.56-16.62)$ & 0.027 & 0.094 \\
\hline rs1822744 * & TOPBP1 & $A>G$ & add & $1.86(1.1-3.13)$ & 0.021 & $1.24(0.69-2.24)$ & 0.473 & $1.55(1.05-2.3)$ & 0.027 & 0.317 \\
\hline rs11078671* & RPA1 & $\mathrm{C}>\mathrm{A}$ & rec & $4.17(1.19-14.61)$ & 0.026 & $1.69(0.5-5.71)$ & 0.400 & $2.62(1.08-6.36)$ & 0.031 & 0.311 \\
\hline rs401549^^ & BLM & $A>G$ & add & $1.91(1.14-3.2)$ & 0.013 & $1.08(0.54-2.17)$ & 0.821 & $1.51(0.87-2.62)$ & 0.034 & 0.197 \\
\hline rs1776139* & EXO1 & $A>C$ & dom & $0.45(0.21-0.98)$ & 0.044 & $0.69(0.28-1.68)$ & 0.414 & $0.54(0.3-0.97)$ & 0.040 & 0.479 \\
\hline rs10514249* & XRCC4 & $A>G$ & rec & $0.39(0.17-0.89)$ & 0.024 & $0.86(0.27-2.69)$ & 0.792 & $0.52(0.25-1.09)$ & 0.047 & 0.273 \\
\hline
\end{tabular}

\# adjusted for age, sex, pack year, clinical stage, performance status, concurrent chemoradiotherapy, radiation treatment type, FEV1 percentage, DLCO percentage, PTV volume, mean esophagus dose and mean lung dose; * Use proxy SNP in validation; ${ }^{\wedge}$ Re-genotyped in GWAS population using original SNP found in the discovery phase; \& Use proxy SNP rs7175811 in validation stage from GWAS data; Abbreviations: Dom, dominant; Rec, recessive; Add, additive; P-het, P for heterogeneity.

Table 3. Eight DNA double-strand break repair pathway related SNPs with same trend effects on radiation pneumonitis across two analytical phases.

\begin{tabular}{|c|c|c|c|c|c|c|c|c|c|c|}
\hline \multirow[b]{2}{*}{ SNP } & \multirow[b]{2}{*}{ Gene } & \multirow[b]{2}{*}{ Allele } & \multirow[b]{2}{*}{ Model } & \multicolumn{2}{|c|}{ Discovery } & \multicolumn{2}{|c|}{ Validation } & \multicolumn{2}{|c|}{ Meta } & \multirow[b]{2}{*}{ P-het } \\
\hline & & & & $\mathrm{OR}^{\#}(95 \% \mathrm{CI})$ & $p$ value & $\mathrm{OR}^{\#}(95 \% \mathrm{CI})$ & $p$ value & OR $(95 \% \mathrm{CI})$ & $p$ value & \\
\hline rs1051772^ & TOPBP1 & $A>G$ & dom & $0.27(0.11-0.65)$ & 0.004 & $0.41(0.13-1.27)$ & 0.122 & $0.32(0.16-0.63)$ & 0.001 & 0.564 \\
\hline rs16944739 * & BLM & $\mathrm{G}>\mathrm{A}$ & rec & $3.11(1.13-8.56)$ & 0.028 & $6.24(0.68-57.4)$ & 0.106 & $3.51(1.40-8.81)$ & 0.008 & 0.576 \\
\hline rs3735461^ & RPA3 & $A>G$ & dom & $2.90(1.39-6.04)$ & 0.005 & $1.41(0.61-3.24)$ & 0.418 & $2.11(1.22-3.66)$ & 0.008 & 0.204 \\
\hline rs963248* & XRCC4 & $A>G$ & dom & $1.92(1.01-3.63)$ & 0.047 & $2.02(0.84-4.83)$ & 0.115 & $1.95(1.16-3.27)$ & 0.011 & 0.925 \\
\hline rs3760412* & EME1 & $A>G$ & dom & $0.42(0.22-0.79)$ & 0.008 & $0.84(0.39-1.79)$ & 0.651 & $0.56(0.34-0.91)$ & 0.019 & 0.170 \\
\hline rs11571468 & RAD52 & $G>A$ & dom & $0.35(0.13-0.95)$ & 0.040 & $0.55(0.17-1.73)$ & 0.305 & $0.43(0.20-0.90)$ & 0.026 & 0.566 \\
\hline rs4986764* & BRIP1 & $\mathrm{G}>\mathrm{A}$ & rec & $2.42(1.08-5.45)$ & 0.032 & $1.53(0.52-4.56)$ & 0.443 & $2.06(1.07-3.95)$ & 0.030 & 0.509 \\
\hline rs917029* & EME1 & $A>G$ & rec & $2.57(1.09-6.08)$ & 0.031 & $1.53(0.50-4.65)$ & 0.456 & $2.12(1.07-4.18)$ & 0.030 & 0.467 \\
\hline
\end{tabular}

\# adjusted for age, sex, pack year, clinical stage, performance status, concurrent chemoradiotherapy, radiation treatment type, FEV1 percentage, DLCO percentage, PTV volume, mean lung dose; * use proxy SNP in validation; ^ Re-genotyped using original SNP found in discovery phase. 
Table 4. Unfavorable genotype (UFG) analysis for radiation-induced toxicities.

\begin{tabular}{|c|c|c|c|c|c|}
\hline UFG Group & Number of UFGS & Grade $\geqslant 2 n(\%)$ & Grade $<2 n(\%)$ & Adjusted OR * $(95 \%$ CI $)$ & $p$ Value \\
\hline \multicolumn{6}{|c|}{ Esophagitis } \\
\hline 0 & $0-5$ & $68(48.92 \%)$ & $71(51.08 \%)$ & 1 (reference) & \\
\hline 1 & $6-7$ & $53(63.86 \%)$ & $30(36.14 \%)$ & $3.63(1.56-8.43)$ & 0.003 \\
\hline 2 & $8-10$ & $21(84.00 \%)$ & $4(16.00 \%)$ & $113.12(14.73-868.67)$ & $5.46 \times 10^{-6}$ \\
\hline \multicolumn{2}{|c|}{$p$ trend for individual UFG } & & & $1.78(1.43-2.22)$ & $2.59 \times 10^{-7}$ \\
\hline \multicolumn{6}{|c|}{ Pneumonitis } \\
\hline 0 & $0-2$ & $4(9.76 \%)$ & $37(90.24 \%)$ & 1 (reference) & \\
\hline 1 & $3-5$ & $72(40.45 \%)$ & $106(59.55 \%)$ & $8.65(2.73-27.38)$ & 0.0002 \\
\hline 2 & $6-8$ & $11(78.57 \%)$ & $3(21.43 \%)$ & $73.05(11.28-472.94)$ & $6.70 \times 10^{-6}$ \\
\hline \multicolumn{2}{|c|}{$p$ trend for individual UFG } & & & $2.49(1.79-3.46)$ & $6.34 \times 10^{-8}$ \\
\hline
\end{tabular}

* Adjusted for age, sex, pack year, clinical stage, performance status, concurrent chemoradiotherapy, radiation treatment type, FEV1 percentage, DLCO percentage, PTV volume, mean dose (pneumonitis: mean lung dose; esophagitis: mean esophagus dose and mean lung dose).

\subsection{In Silico SNP Function Prediction}

To further investigate the identified variants and explore potential mechanisms, we used bioinformatics tools to evaluate their effects on protein structure and function (Table 5). HaploReg identified that six SNPs were located in enhancer histone marks (rs2270132, rs1822744, rs401549, rs16944739, rs3735461 and rs11571468). rs3735461, which was associated with an increased risk of pneumonitis, was predicted to occur in protein-binding regions and also in promoter histone mark sites. 16 SNPs were predicted to alter regulatory binding motifs, and 7 SNPs (rs2270132, rs10514249, rs1051772, rs16944739, rs3735461, rs11571468 and rs917029) were located in DNase sites.

Homozygous variant GG genotype of rs1799966 in BRCA1 was a missense variant that was associated with increased risk of radiation esophagitis. The polymorphism results in amino acid change from a polar and uncharged serine to a nonpolar uncharged glycine. SIFT (SIFT score: 0.02), SNPeffect and SNPs3D analysis indicated this amino acid change may have a deleterious effect on protein function. Another missense SNP, BRIP1:rs4986764, which was associated with increased risk of radiation pneumonitis. This variant results in amino acid change from a polar and uncharged serine residue to a nonpolar uncharged proline. SNPeffect analysis indicated this amino acid substitution may have a deleterious effect on protein function.

\subsection{Gene-Based Analysis}

We further used VEGAS to perform gene-based tests to summarize the effect of SNPs within a single gene on toxicities (Table 6). In total, 7 genes (EXO1, RPA1, MDC1, BLM, RAD54L, BRCA1, $P R K D C)$ were significantly associated with radiation-induced esophagitis, among which EXO1 had the smallest $p$ value $(p=0.005)$. 6 genes (RAD54L, MUS81, RAG1, RAG2, EME1, ATM) were found to be significantly associated with radiation-induced pneumonitis, among which $R A D 54 L$ had the smallest $p$ value $(p=0.033)$. 
Table 5. SNP function prediction.

\begin{tabular}{|c|c|c|c|c|c|c|c|c|c|c|}
\hline SNP & Related Outcome & Gene & Position & $\begin{array}{c}\text { Enhancer } \\
\text { Histone Marks }\end{array}$ & DNase & $\begin{array}{l}\text { Promoter } \\
\text { Histone } \\
\text { Marks }\end{array}$ & $\begin{array}{l}\text { Proteins } \\
\text { Bound }\end{array}$ & Motifs Changed & Amino Acid Change & eQTL \\
\hline rs7165790 & esophagitis & BLM & intronic & - & - & - & - & Barhl1,Zbtb12 & - & - \\
\hline rs8176257 & esophagitis & BRCA1 & intronic & - & - & - & - & Pax-4,TATA & - & $\mathrm{Y}$ \\
\hline rs2270132 & esophagitis & BLM & intronic & HSMM & 4 cell types & - & - & Zfp740 & - & - \\
\hline rs12516 & esophagitis & BRCA1 & 3'-UTR & - & - & - & - & 9 altered motifs & - & $\mathrm{Y}$ \\
\hline rs1799966 & esophagitis & BRCA1 & Missense & - & - & - & - & - & $\mathrm{S}[\mathrm{Ser}] \Rightarrow \mathrm{G}[\mathrm{Gly}]$ & $\mathrm{Y}$ \\
\hline rs4873772 & esophagitis & PRKDC & intronic & - & - & - & - & CEBPD,EWSR1-FLI1,HDAC2 & - & - \\
\hline rs1822744 & esophagitis & TOPBP1 & intronic & Huvec & - & - & - & DBP,INSM1,Pax-2 & - & - \\
\hline rs11078671 & esophagitis & RPA1 & intronic & - & - & - & - & $\mathrm{CIZ}, \mathrm{E} 2 \mathrm{~F}$ & - & - \\
\hline rs401549 & esophagitis & BLM & intronic & HMEC & - & - & - & Foxj1,Pax-3,Sox & - & - \\
\hline rs1776139 & esophagitis & EXO1 & intronic & - & - & - & - & 4 altered motifs & - & - \\
\hline rs10514249 & esophagitis & XRCC4 & intronic & - & WERI-Rb-1 & - & - & - & - & - \\
\hline rs1051772 & pneumonitis & TOPBP1 & synonymous & - & $\begin{array}{l}5 \text { cell types } \\
\text { GM12878, }\end{array}$ & - & - & 21 altered motifs & - & - \\
\hline rs16944739 & pneumonitis & BLM & intronic & K562, GM12878 & $\begin{array}{l}\text { GM12892, } \\
\text { GM12864 }\end{array}$ & - & - & TCF12 & - & - \\
\hline rs3735461 & pneumonitis & RPA3 & intronic & Huvec & 18 cell types & - & $\begin{array}{l}5 \text { bound } \\
\text { proteins }\end{array}$ & Foxc1,STAT & - & - \\
\hline rs963248 & pneumonitis & XRCC4 & intronic & - & - & - & - & VDR & - & - \\
\hline rs3760412 & pneumonitis & EME1 & intronic & - & - & - & - & LBP-1,LXR & - & - \\
\hline rs11571468 & pneumonitis & RAD52 & intronic & NHEK & Hepatocytes & - & - & - & - & - \\
\hline rs4986764 & pneumonitis & BRIP1 & Missense & - & - & - & - & SIX5,THAP1,Znf143 & $\mathrm{S}[\mathrm{Ser}] \Rightarrow \mathrm{P}[\mathrm{Pro}]$ & - \\
\hline rs917029 & pneumonitis & EME1 & intronic & - & HL-60 & - & - & 5 altered motifs & - & - \\
\hline
\end{tabular}


Table 6. VEGAS Results for the significant genes for radiation esophagitis and pneumonitis from discovery set.

\begin{tabular}{cccc}
\hline Gene & Chr & Number of SNPS & $p$ Value \\
\hline Esophagitis & & & \\
\hline EXO1 & 1 & 23 & 0.005 \\
RPA1 & 17 & 16 & 0.009 \\
MDC1 & 6 & 5 & 0.014 \\
BLM & 15 & 23 & 0.018 \\
RAD54L & 1 & 18 & 0.023 \\
BRCA1 & 17 & 10 & 0.024 \\
PRKDC & 8 & 11 & 0.036 \\
\hline Pneumonitis & & & \\
\hline RAD54L & 1 & 18 & 0.033 \\
MUS81 & 11 & 6 & 0.036 \\
RAG1 & 11 & 7 & 0.039 \\
RAG2 & 11 & 7 & 0.039 \\
EME1 & 17 & 10 & 0.048 \\
ATM & 11 & 10 & 0.049 \\
\hline
\end{tabular}

\section{Discussion}

RT destroys tumor cells mainly by damaging their DNA, especially double-strand DNA. However, such an effect also occurs in normal cells. An individual's capacity for repairing DNA damage may determine the presence and extent of radiation toxicities. It has been known for years that genetic variations in DNA repair genes might regulate patients' sensitivity to RT [1]. In this study, we systematically investigated genetic variation within DSB repair pathway as potential predictive biomarkers for radiation-induced esophagitis and pneumonitis in NSCLC patients treated with definitive radiation or concurrent chemoradiation. To control for false discovery, a validation step was also included. We found that an intronic SNP BLM:rs7165790 was significantly associated with a decreased risk of esophagitis in both the discovery and validation populations. A strong cumulative effect was observed for these SNPs on radiation toxicities.

The most significant SNP for esophagitis was an intronic variant BLM:rs7165790. Bloom syndrome (BS) gene product, $B L M$, encodes the protein RecQL3 helicase, an enzyme that restores malfunctioning replication forks during DNA replication. The RecQ helicase BLM has been also shown to be involved in single-strand DNA resection at the initial stages of homologous recombination $[27,28]$. Grabarz et al. found that BLM is an essential factor involved in DSB repair initiation and is essential for the maintenance of genome stability [29]. Mutations in BLM could lead to Bloom syndrome, which is an autosomal-recessive genetic disorder that is associated with increased levels of spontaneous sister-chromatid exchanges (SCEs), genome instability, as well as elevated cancer susceptibility [30]. Broberg et al. performed a case-control study to indicate that a variant allele of rs2532105 in BLM showed increased risk for breast cancer [31]. In our study, BLM:rs7165790 was the only SNP validated to be associated with decreased risk of developing esophagitis. Gene-based test also showed that BLM was among the most significant genes associated with risk of esophagitis. All these results support that this gene plays an important role in radiation-induced esophagitis. Although located in the intron region where its function was not obvious, rs7165790 was identified as borderline significant in expression quantitative trait locus (eQTL) relationship with $B L M(p=0.0644)$. It is possible that this SNP, or other SNPs tagged by it, could contribute to the alteration of BLM expression, which warrants further investigation.

For the radiation-induced pneumonitis, the top SNP was synonymous with SNP rs1051772 in TOPBP1, which was significantly associated with decreased risk of radiation-induced pneumonitis and showed the same trend of effects between discovery and validation populations and reached 
statistical significance in the combined meta-analysis. Increasing evidence has indicated that TOPBP1 participated in DNA replication checkpoint control and played important roles in maintaining genomic stability [32]. SNPs in TOPBP1 were also associated with some cancer risks [10,11]. The mechanisms underlying radiation-induced toxicities need to be further explored. MUS81 was the top gene that was significantly associated with radiation-induced pneumonitis by gene-based analysis. 3 SNPs (rs13817, rs558114 and rs635375) in MUS81 were shown to be significantly related to radiation-induced pneumonitis in the discovery group only, and the exact function is still unclear. The N-terminus was also proposed to contain a BLM-interacting domain [33], and whether these two genes interact with each other in mediating radiation toxicities needs to be further studied.

Previous studies have reported the association of ATM polymorphisms with radiation-induced esophagitis [34-36]. In our study, we did not find a similar association, although 10 genetic variants tagging the ATM gene were included in the analysis. Since most of the prior reports are candidate gene studies genotyping a limited number of SNPs in the Asian population while our study is pathway-based in the non-Hispanic white population, differences in study design and demographic group may affect the final results.

Interestingly, we did not find overlapping SNPs between esophagitis and pneumonitis, suggesting that different biological mechanisms or responses to chemoradiation-induced damage may play a role in the development of these toxicities. This is supported by our finding that compared to radiation-only treatment, concurrent chemoradiation treatment did not seem to affect the distribution of patients with pneumonitis but significantly increased the incidence of esophagitis (Supplementary Table S6). However, since this study only focused on genetic variants in the DSB pathway, we could not rule out that other pathways, such as inflammation, might share common susceptibility factors for esophagitis and pneumonitis. Future whole-genome profiles of genetic variation associated with these adverse events are necessary to find the most significant and/or common genetic factors for clinical application.

Our study has several advantages. First, other than single genes, we systematically investigated the effects of genetic variations (440 SNPs) within major genes in DNA-DSB repair pathway (44 genes). Second, we performed the first comprehensive dosimetric and clinical data collection to enable this pathway-based analysis. Moreover, to reduce the potential false positive findings, we adopted a two-phase screening and validation approach in the analysis.

There were, however, some limitations to this study. First, the sample size was relatively small due to the fact that radiation therapy is mostly used in late-stage patients in our population, while the majority of patients were treated initially by surgery or by a combination of surgery and chemotherapy. However, the sample size is relatively large compared to other studies of this kind [37]. Second, although we included an internal validation group, the possibility of false positives still exists. Future external independent validation should be included to further validate our findings.

In summary, this is the first pathway-based study for association between single nucleotide polymorphisms in DNA DSB repair pathway genes and risk of radiation-induced pneumonitis and esophagitis for NSCLC Patients. Our results provide strong support for the claim that DSB pathway-related genetic variations serve as a potential biomarker to predict radiation toxicities and further guide the RT for NSCLC patients. With further investigations, we can test the predictive value by combining these significant SNPs with some commonly used variables in clinics that may be also related to radiation toxicities.

Supplementary Materials: Supplementary materials are available online at http://www.mdpi.com/ 2072-6694/8/2/23/s1.

Acknowledgments: This study was supported by U.S. NIH grants, P50CA070907 (J.D. Minna, J.A. Roth, and X. $\mathrm{Wu}$ ), and CPRIT RP130502 (X. Wu). Additional support was provided by the Center for Translational and Public Health Genomics of the Duncan Family Institute for Cancer Prevention and Risk Assessment, The University of Texas MD Anderson Cancer Center (X. Wu).

Author Contributions: X.W. conceived and designed the experiments; L.Z. and X.P. performed the experiments; L.Z., X.P., Y.Y., and X.W. analyzed the data; C.L. and J.C. recruited patients and contributed samples $/ \mathrm{materials;}$ and L.Z., X.P., and X.W. wrote the paper. 
Conflicts of Interest: The authors declare no conflict of interest.

\section{References}

1. Chang-Claude, J.; Popanda, O.; Tan, X.L.; Kropp, S.; Helmbold, I.; von Fournier, D.; Haase, W.; Sautter-Bihl, M.L.; Wenz, F.; Schmezer, P.; et al. Association between polymorphisms in the DNA repair genes, XRCC1, APE1, and XPD and acute side effects of radiotherapy in breast cancer patients. Clin. Cancer Res. 2005, 11, 4802-4809. [CrossRef] [PubMed]

2. Kelsey, C.R.; Rosenstein, B.S.; Marks, L.B. Predicting toxicity from radiation therapy—It's genetic, right? Cancer 2012, 118, 3450-3454. [CrossRef] [PubMed]

3. Stenmark, M.H.; Cai, X.W.; Shedden, K.; Hayman, J.A.; Yuan, S.; Ritter, T.; Ten Haken, R.K.; Lawrence, T.S.; Kong, F.M. Combining physical and biologic parameters to predict radiation-induced lung toxicity in patients with non-small-cell lung cancer treated with definitive radiation therapy. Int. J. Radiat. Oncol. Biol. Phys. 2012, 84, e217-e222. [CrossRef] [PubMed]

4. Yin, M.; Liao, Z.; Huang, Y.J.; Liu, Z.; Yuan, X.; Gomez, D.; Wang, L.E.; Wei, Q. Polymorphisms of homologous recombination genes and clinical outcomes of non-small cell lung cancer patients treated with definitive radiotherapy. PLoS ONE 2011, 6, e20055. [CrossRef] [PubMed]

5. Qiao, G.B.; Wu, Y.L.; Yang, X.N.; Zhong, W.Z.; Xie, D.; Guan, X.Y.; Fischer, D.; Kolberg, H.C.; Kruger, S.; Stuerzbecher, H.W. High-level expression of RAD51 is an independent prognostic marker of survival in non-small-cell lung cancer patients. Br. J. Cancer 2005, 93, 137-143. [CrossRef] [PubMed]

6. Ohnishi, K.; Scuric, Z.; Schiestl, R.H.; Okamoto, N.; Takahashi, A.; Ohnishi, T. SiRNA targeting NBS1 or XIAP increases radiation sensitivity of human cancer cells independent of TP53 status. Radiat. Res. 2006, 166, 454-462. [CrossRef] [PubMed]

7. Yanagisawa, T.; Urade, M.; Yamamoto, Y.; Furuyama, J. Increased expression of human DNA repair genes, XRCC1, XRCC3 and RAD51, in radioresistant human KB carcinoma cell line N10. Oral Oncol. 1998, 34, 524-528. [CrossRef]

8. Tambini, C.E.; Spink, K.G.; Ross, C.J.; Hill, M.A.; Thacker, J. The importance of XRCC2 in RAD51-related DNA damage repair. DNA Repair 2010, 9, 517-525. [CrossRef] [PubMed]

9. Kelsey, C.R.; Jackson, I.L.; Langdon, S.; Owzar, K.; Hubbs, J.; Vujaskovic, Z.; Das, S.; Marks, L.B. Analysis of single nucleotide polymorphisms and radiation sensitivity of the lung assessed with an objective radiologic endpoin. Clin. Lung Cancer 2013, 14, 267-274. [CrossRef] [PubMed]

10. Yang, M.; Zhang, L.; Bi, N.; Ji, W.; Tan, W.; Zhao, L.; Yu, D.; Wu, C.; Wang, L.; Lin, D. Association of P53 and ATM polymorphisms with risk of radiation-induced pneumonitis in lung cancer patients treated with radiotherapy. Int. J. Radiat. Oncol. Biol. Phys. 2011, 79, 1402-1407. [CrossRef] [PubMed]

11. Zhang, L.; Yang, M.; Bi, N.; Fang, M.; Sun, T.; Ji, W.; Tan, W.; Zhao, L.; Yu, D.; Lin, D.; et al. ATM polymorphisms are associated with risk of radiation-induced pneumonitis. Int. J. Radiat. Oncol. Biol. Phys. 2010, 77, 1360-1368. [CrossRef] [PubMed]

12. Yin, M.; Liao, Z.; Liu, Z.; Wang, L.E.; O’Reilly, M.; Gomez, D.; Li, M.; Komaki, R.; Wei, Q. Genetic variants of the nonhomologous end joining gene LIG4 and severe radiation pneumonitis in nonsmall cell lung cancer patients treated with definitive radiotherapy. Cancer 2012, 118, 528-535. [CrossRef] [PubMed]

13. Hildebrandt, M.A.; Komaki, R.; Liao, Z.; Gu, J.; Chang, J.Y.; Ye, Y.; Lu, C.; Stewart, D.J.; Minna, J.D.; Roth, J.A.; et al. Genetic variants in inflammation-related genes are associated with radiation-induced toxicity following treatment for non-small cell lung cancer. PLoS ONE 2010, 5, e12402. [CrossRef] [PubMed]

14. Trotti, A.; Colevas, A.D.; Setser, A.; Rusch, V.; Jaques, D.; Budach, V.; Langer, C.; Murphy, B.; Cumberlin, R.; Coleman, C.N.; et al. CTCAE v3.0: Development of a comprehensive grading system for the adverse effects of cancer treatment. Semin. Radiat. Oncol. 2003, 13, 176-181. [CrossRef]

15. Chang, J.Y.; Liu, H.; Balter, P.; Komaki, R.; Liao, Z.; Welsh, J.; Mehran, R.J.; Roth, J.A.; Swisher, S.G. Clinical outcome and predictors of survival and pneumonitis after stereotactic ablative radiotherapy for stage I non-small cell lung cancer. Radiat. Oncol. 2012, 7, 152. [CrossRef] [PubMed]

16. Palma, D.A.; Senan, S.; Tsujino, K.; Barriger, R.B.; Rengan, R.; Moreno, M.; Bradley, J.D.; Kim, T.H.; Ramella, S.; Marks, L.B. Predicting radiation pneumonitis after chemoradiation therapy for lung cancer: An international individual patient data meta-analysis. Int. J. Radiat. Oncol. Biol. Phys. 2013, 85, 444-450. [CrossRef] [PubMed] 
17. Wu, X.; Spitz, M.R.; Lee, J.J.; Lippman, S.M.; Ye, Y.; Yang, H.; Khuri, F.R.; Kim, E.; Gu, J.; Lotan, R.; et al. Novel susceptibility loci for second primary tumors/recurrence in head and neck cancer patients: Large-scale evaluation of genetic variants. Cancer Prev. Res. 2009, 2, 617-624. [CrossRef] [PubMed]

18. The International HapMap Consortium. The International HapMap Project. Nature 2003, 426, 789-796.

19. Pu, X.; Hildebrandt, M.A.; Lu, C.; Roth, J.A.; Stewart, D.J.; Zhao, Y.; Heist, R.S.; Ye, Y.; Chang, D.W.; Su, L.; et al Inflammation-related genetic variations and survival in patients with advanced non-small cell lung cancer receiving first-line chemotherapy. Clin. Pharmacol. Therap. 2014, 96, 360-369. [CrossRef] [PubMed]

20. Johnson, A.D.; Handsaker, R.E.; Pulit, S.; Nizzari, M.M.; O'Donnell, C.J.; de Bakker, P.I.W. SNAP: A web-based tool for identification and annotation of proxy SNPs using HapMap. Bioinformatics 2008, 24, 2938-2939. [CrossRef] [PubMed]

21. Ward, L.D.; Kellis, M. HapploReg: a resource for exploring chromatin states, conservation, and regulatory motif alterations within sets of genetically linked variant. Nuvleic Acids Res. 2012, 40, D930-D934. [CrossRef] [PubMed]

22. Adzhubei, I.A.; Schmidt, S.; Peshkin, L.; Ramensky, V.E.; Gerasimova, A.; Bork, P.; Kondrashov, A.S.; Sunyaev, S.R. A method and server for predicting damaging missense mutations. Nat. Methods 2010, 7, 248-249. [CrossRef] [PubMed]

23. Reumers, J.; Schymkowitz, J.; Ferkinghoff-Borg, J.; Stricher, F.; Serrano, L.; Rousseau, F. Snpeffect: A database mapping molecular phenotypic effects of human non-synonymous coding snps. Nucleic Acids Res. 2005, 33, D527-D532. [CrossRef] [PubMed]

24. Kumar, P.; Henikoff, S.; Ng, P.C. Predicting the effects of coding non-synonymous variants on protein function using the sift algorithm. Nat. Protoc. 2009, 4, 1073-1081. [CrossRef] [PubMed]

25. Yue, P.; Melamud, E.; Moult, J. SNPS3D: Candidate gene and snp selection for association studies. BMC Bioinform. 2006, 7, 166. [CrossRef] [PubMed]

26. Liu, J.Z.; McRae, A.F.; Nyholt, D.R.; Medland, S.E.; Wray, N.R.; Brown, K.M.; Investigators, A.; Hayward, N.K.; Montgomery, G.W.; Visscher, P.M.; et al. A versatile gene-based test for genome-wide association studies. Am. J. Hum. Genet. 2010, 87, 139-145. [CrossRef] [PubMed]

27. Gravel, S.; Chapman, J.R.; Magill, C.; Jackson, S.P. DNA helicases SGS1 and BLM promote DNA double-strand break resection. Genes Dev. 2008, 22, 2767-2772. [CrossRef] [PubMed]

28. Nimonkar, A.V.; Genschel, J.; Kinoshita, E.; Polaczek, P.; Campbell, J.L.; Wyman, C.; Modrich, P.; Kowalczykowski, S.C. BLM-DNA2-RPA-MRN and EXO1-BLM-RPA-MRN constitute two DNA end resection machineries for human DNA break repair. Genes Dev. 2011, 25, 350-362. [CrossRef] [PubMed]

29. Grabarz, A.; Guirouilh-Barbat, J.; Barascu, A.; Pennarun, G.; Genet, D.; Rass, E.; Germann, S.M.; Bertrand, P.; Hickson, I.D.; Lopez, B.S. A role for BLM in double-strand break repair pathway choice: Prevention of ctip/mre11-mediated alternative nonhomologous end-joining. Cell Rep. 2013, 5, 21-28. [CrossRef] [PubMed]

30. Chu, W.K.; Hickson, I.D. Recq helicases: Multifunctional genome caretakers. Nat. Rev. Cancer 2009, 9 , 644-654. [CrossRef] [PubMed]

31. Broberg, K.; Huynh, E.; Schlawicke Engstrom, K.; Bjork, J.; Albin, M.; Ingvar, C.; Olsson, H.; Hoglund, M. Association between polymorphisms in RMI1, TOP3A, and BLM and risk of cancer, a case-control study. BMC Cancer 2009, 9, 140. [CrossRef] [PubMed]

32. Bartek, J.; Mailand, N. Topping up atr activity. Cell 2006, 124, 888-890. [CrossRef] [PubMed]

33. Forma, E.; Brzezianska, E.; Krzeslak, A.; Chwatko, G.; Jozwiak, P.; Szymczyk, A.; Smolarz, B.; Romanowicz-Makowska, H.; Rozanski, W.; Brys, M. Association between the c. ${ }^{*} 229 \mathrm{c}>\mathrm{t}$ polymorphism of the topoisomerase iibeta binding protein 1 (TopBP1) gene and breast cancer. Mol. Biol. Rep. 2013, 40, 3493-3502. [CrossRef] [PubMed]

34. Forma, E.; Wojcik-Krowiranda, K.; Jozwiak, P.; Szymczyk, A.; Bienkiewicz, A.; Brys, M.; Krzeslak, A. Topoisomerase iibeta binding protein 1 c. ${ }^{* 229 c>t}$ (rs115160714) gene polymorphism and endometrial cancer risk. Pathol. Oncol. Res. 2014, 20, 597-602. [CrossRef] [PubMed]

35. Zhang, R.; Sengupta, S.; Yang, Q.; Linke, S.P.; Yanaihara, N.; Bradsher, J.; Blais, V.; McGowan, C.H.; Harris, C.C. BLM helicase facilitates Mus81 endonuclease activity in human cells. Cancer Res. 2005, 65, 2526-2531. [CrossRef] [PubMed] 
36. Xiong, H.; Liao, Z.; Liu, Z.; Xu, T.; Wang, Q.; Liu, H.; Komaki, R.; Gomez, D.; Wang, L.E.; Wei, Q. ATM polymorphisms predict severe radiation pneumonitis in patients with non-small cell lung cancer treated with definitive radiation therapy. Int. J. Radiat. Oncol. Biol. Phys. 2013, 85, 1066-1073. [CrossRef] [PubMed]

37. Yin, M.; Liao, Z.; Liu, Z.; Wang, L.E.; Gomez, D.; Komaki, R.; Wei, Q. Functional polymorphisms of base excision repair genes XRCC1 and APEX1 predict risk of radiation pneumonitis in patients with non-small cell lung cancer treated with definitive radiation therapy. Int. J. Radiat. Oncol. Biol. Phys. 2011, 81, e67-e73. [CrossRef] [PubMed]

(C) 2016 by the authors; licensee MDPI, Basel, Switzerland. This article is an open access article distributed under the terms and conditions of the Creative Commons by Attribution (CC-BY) license (http://creativecommons.org/licenses/by/4.0/). 